\title{
Evaluation of the Relationship between Accounting Variables and Timelines of Annual Reports of Accepted Companies in Tehran Stock Exchange
}

\author{
1Ghasem Hamidi \\ ${ }^{2 H a b i b o l l a h ~ R a s o u l i ~}$
}

\author{
${ }^{1}$ MSc. Student, Khorram Shahr International Center, Persian Gulf Center, Iran; mh.cash@yahoo.com \\ 2Ph.D. Student And Faculty Member At Islamic Azad University Of Abadan, Iran; h_rasoli1348 @yahoo.com
}

Doi:10.5901/mjss.2016.v7n4s2p117

\section{Abstract}

One of the main aims of financial reporting and providing financial bills is to create useful information for stock holders, customers, creditors, governmental organizations and people in order to make decision. On the other hand, that information can be considered as relative one which is provided timely. If the information isn't provided timely, it will lose its usefulness for decision making and judgments of users. Obviously, the one who has access to accounting information earlier can make better decisions. This research evaluates the relationship between accounting variables and timely annual financial reports of Tehran stock exchange. Evaluation of hypothesis used combined data statistical method between 2009 and 2015 using the information of 160 companies via systematic elimination sampling method. Research results showed that there is a negative and reverse relationship between current ratio, assets return and equity and profitability of stock holders and timely reports and it reduces days of delay in financial reporting and provides better financial bills. It also showed that there is a direct positive relationship between financial leverage and timely financial reports but there were no meaningful relationship between company size and timely financial reports.

Keywords: current ratio, financial leverage, assets return, profitability, timely financial reporting

\section{Introduction}

One of the main aims of financial reporting and providing financial bills is to create useful information for stock holders, customers, creditors, governmental organizations and people in order to make decision. Financial reporting term means financial bills and other published reports by a business section for users.

According to financial accounting statement concepts (statement 2), those information are considered as relative which are timely provided. If the information is not provided timely, it will lose its usefulness for decision making and judgment. Obviously, the one who has access to accounting information earlier can make better decision. Therefore, capital businesses emphasize timely information publishing in order for the users to have equal access to the information and deals be based on real information and they can avoid information publishing according to rumors.

In other words, financial information must be provided for users before the time in which they can make decisions according to them. As the information is sensitive to passing of time and loses its value during time, the more the information near to the happening, the more its usefulness. As an example we can mention nearness of reports to ending date of financial reporting. According to the importance of this subject, this research aims at evaluation of the relationships between important accounting variables and timely financial reporting in Tehran stock exchange.

\section{Research Theories}

The reason of accounting is demands for financial information and accountants and business section have required ability and interest for providing the information. Therefore, concepts such as quality which is used for goods and services is able to be followed and discussed for accounting services including final product. Financial accounting quality is a term which separates useful and beneficial information from other ones and increases information profitability. Timely financial reports is one of the most important elements of providing financial information quality of companies because timely information can result in using better and more beneficial information which is provided by accounting system end product. Therefore, reporting speed means the amount of time delay in providing financial reports of companies and must be considered by financial report providers. Increase of reporting speed can result in better financial information of 
companies and clearer capital market because of using timely information in making economical decision makings by investors. It can have high impact on attractiveness of financial and capital market.

As financial reports are means of unveiling valid and credible financial information to which public can have access, it reduces improper decision making by investors in case of being untimely via reducing private information. Therefore, it can be thought that timely information reduces lack of informational asymmetry among investors. The high quality financial reporting companies have less sensibility facing macro consequences of economy. This shows that there is a relationship between reporting mechanism and functionality of investment and high reporting quality reduces moral danger and improper decision making (Moradi and Pour Hosseini, 2009).

Timely reporting is a function of many factors. These factors usually are divided into two groups. The first group relates to audit and auditor and the second group relate to company features and resulted in accounting variables of management. Audit factors are those which play a role in executing auditory tasks and providing timely reports (e.g. size of auditory company, auditor's expertise, etc). The company and management related factors are those which enable manager to provide annual and timely reports or reduce the costs which relate to delay of reporting (e.g. size of company, current ratio, financial leverage, profitability etc.). This research only considers some of company and management related factors.

According to above, the aim of this research is to find the relationship between accounting variables and timely financial reporting and the question is that if these variables cause delay in or facilitate financial reporting?

\section{Review of Literature}

Esmaeil and Chendler (2005) evaluated timely intra-period financial reports of Malaysian companies. In order to this, 177 stock exchange companies of Kuala Lumpur were chosen for a three month period until 30 Sep 2001. They evaluated the relationship between timeliness and four company features that is size, profitability, growth and company's leverage. The results show that bigger, more profitable, more developing and having less leverage usually report earlier. All the 117 companies provided their reporting in two months except one of them.

Wang and Sung (2006) used 8249 financial reporting of accepted companies in Jensen and Shanghai stock exchange between 1993 and 2003 in order to evaluate timely financial reporting in Chinese companies. They considered effective factors on reporting including auditor's comments, profitability, company's size, company's type, stock type and stock place. The results of descriptive analysis showed that the average of financial reporting delay were 88 days and the regression results showed that there is a meaningful relationship between auditor's comment, profitability, company's size and type and stock exchange place and delay in financial reporting.

Maha Jan and Chender (2008) evaluated the relationship between timely financial reports and company's features in India. The research was done according to annual financial reports of 229 and 229 companies in 2005 and 2006. Descriptive statistic results show that almost all the companies provide timely reports in 180 days. The relationship between company's size, profitability, industry type, age, leverage, and underwriting group, place of company, costs of auditory, size of auditory company and its complexity and time of reporting was evaluated. The findings showed that there is only a meaningful relationship between company's size, industry type, auditory institute size and reporting time in two studying years.

Ahmad and Abedin (2009) studied delay in annual financial reporting in Malaysian stock exchange. The sample included 342 companies among 413 ones and the year of research was 1993. The relationship between size, number of dependent companies, type of auditory company, auditor's comment, return of stock holders, the fact that if manager is a stock holder or not, industry type, amount of long-term debt and fiscal year end date and timely financial reports was evaluated and there was found a meaningful relationship between all variables and dependent ones except industry type, leverage and fiscal year end date.

Mostafa and Shivat (2013) studied effective factors on timely annual financial reporting of accepted companies in Jordan's stock exchange. In this study they considered the relationship between some company features including size, profit of each stock, return ration of stock holders, return ratio of sum of assets, divided profit of each stock, company's age, financial leverage, net cash flow from operational actions and timing of providing financial reports. The results showed that only return of assets and return of stock holders' salary and net cash flow from operational actions and divided profit of each stock aren't related to timing of reporting and there is a meaningful relationship between timely financial reports and other variables.

Mahdavi and Jamalian Pour (2009) studied effective factors on speed of annual financial reporting of stock companies between 2001 and 2007. Using multi-variable regression, they evaluated the relationship between size of companies, financial and non-financial ratios, and the proportion of current profit to invest and speed of annual financial 
reporting or time difference between annual auditory and ending financial year of companies. The results showed that reporting speed has meaningful relationship with other financial and non-financial ratios and the companies with lower debt ratio were faster in providing reports.

Asadi et al (2011) evaluated the relationship between company features and timely intra-period financial reporting using a sample including 162 non-financial accepted companies in stock exchange of Teheran between 2003 and 2009. The results showed that size of company and profitability have reverse meaningful relationship with time space of reporting: that is the bigger the company and the more its profitability, the more timely its reports. Other variables didn't have meaningful relationship with reporting.

Khodadad and Arabi (2012) studied the relationship between company's financial operation and timing of financial reports and found out that return of stock holders' salary and changes of return of stock has a positive meaningful relationship with acceleration of financial reports. They also found out that larger companies provide more timely financial reports.

Khoda moradi et al (2012) studied the factors of delay in intra-period financial reporting. This research is according to a sample including 102 companies which are accepted before 1383. The results showed that average of reporting delay was 62 days and analytical results showed that only stock background has meaningful relationship with intra-period financial reporting.

Soleimani Amiri and Rahimi Tamrin (2013) evaluated the relationship between timely financial reporting and financial operations of accepted companies in Tehran stock exchange. Statistical sample of this research included 142 companies during 2007 and 2011. The dependent variable of research is timely financial reporting which can be calculated from time difference between the last valid time of unveiling and reporting time. The independent variables are asset return and return of stock holders' salary. The results showed that timely financial reports has positive and meaningful relationship with asset return and return of stock holders' salary. Therefore, if the companies can use they assets in a more profitable way they can provide timely reports.

\section{Research Hypothesis}

$\mathrm{H} 1$ : there is a meaningful relationship between current ratio and timely annual financial reports of companies.

$\mathrm{H} 2$ : there is a meaningful relationship between financial leverage and timely annual financial reports of companies.

H3: there is a meaningful relationship between asset return and timely annual financial reports of companies.

$\mathrm{H} 4$ : there is a meaningful relationship between stock holders' salary return and timely annual financial reports of companies.

H5: there is a meaningful relationship between company size and timely annual financial reports of companies. H6: there is a meaningful relationship between company profit and timely annual financial reports of companies.

\section{Research method, Data Collection Tools and Statistical Sample}

This research is an applied one naturally and methodologically and a correlation research. This research is semiexperimental and used post-event approach. Library studies and using stock exchange website and also data processing software for companies gathered data from Tehran stock exchange and financial reports and they were used in order to calculate dependent and independent research variables. Therefore, data gathering method is survey. Excel (2010) and EViews (version 8) are used in order to data processing.

Ample of this research include the accepted companies in Tehran stock exchange between 2009 and 2015 (7 years) during which they remained in stock exchange. The sample is justified as using the following conditions:

1- The company must have been accepted in stock exchange before 2009 and have transactions from the beginning of 2009 in stock exchange;

2- End of financial year of company is February and it mustn't have change in financial year during research period;

3- It mustn't have had dealing delay more than one three during the research.

After considering these limitations 160 companies were capable of presence in statistical sample. So they were chosen without sampling.

\section{Regression Model of Research Hypotheses}

The following multi-variable model is used in order to examine research hypotheses: 
Timeliness $_{i t}=\alpha+\beta_{1}$ CRatio $_{i t}+\beta_{2}$ LEVE $_{i t}+\beta_{3}$ ROV $_{i t}+\beta_{4}$ ROA $_{i t}+\beta_{5}$ ROE $_{i t}+\beta_{6}$ SIZE $_{i t}+\beta_{7}$ Profit $_{i t}+\varepsilon_{i t}$ In which timeliness is timely annual financial reports of company,

C Ratio is current ratio;

Lev is financial leverage;

$\mathrm{ROA}$ is return of asset;

ROE is return of shareholders' salary;

Size is companies' size; and

Profit is profitability.

Calculating Research Variables

Dependent Variable: Timeliness

Time of providing annual financial reports can be calculated from end of each year to providing date of financial reporting in annual ordinary general assembly and is considered as a criterion for determining timeliness of financial reporting. As an example, if February is the end of financial year of a company and general assembly meeting date is on June, reporting period will be 124 days for this company.

Independent Variables: Asset Return

Asset return is considered as criteria of operation measurement accounting and is calculated from dividing raw profit on sum of assets. This shows management operation in using resources in order to reach profit.

Return of stockholder's salary

This is one of the operation measurements which is calculated from dividing raw profit on salary of shareholders.

Company size: Logarithm of company selling sum in end of year the company size will be calculated.

Company profit: It is a virtual variable which is one in case of profitability and zero in case of not being profitable.

\section{Information Analysis Method}

Evaluation of research hypotheses used multi-variable regression model depending on combined data approach. The average of this method is that variable dynamic can be calculated during time. In this approach, Chow and $\mathrm{F}$ Limer and Houson examinations are used in order to choose appropriate method.

\subsection{Validity of Variables Evaluation}

Before analysis and examining hypotheses, validity must be evaluated. Validity of variables means that we have fixed average and variance of research variables in different years. Therefore, using these variables won't result in spurious regression. Unit root test has been developed via Im and Shim, Fisher unit root test and dickey Fuller test. The result shows that p.v of all variables is less than $5 \%$ and variables are valid, therefore hypothesis 0 about having the same root will be denied.

Table 1: Unit Root for Variables Test

\begin{tabular}{|c|c|c|c|c|c|c|}
\hline p.v & PP - Fisher & p.v & ADF - Fisher & p.v & Im, Pesaran and Shin & variables \\
\hline 0.00 & 974.5 & 0.00 & 882.11 & 0.00 & -26.42 & TIME \\
\hline 0.00 & 705.7 & 0.00 & 598.5 & 0.00 & -7.7 & CRATIO \\
\hline 0.00 & 557.5 & 0.00 & 485.5 & 0.00 & -3.9 & LEVE \\
\hline 0.00 & 623.4 & 0.00 & 531.1 & 0.00 & -6.2 & ROA \\
\hline 0.00 & 695.2 & 0.00 & 563.4 & 0.00 & -7.1 & ROE \\
\hline 0.00 & 860.7 & 0.00 & 674.4 & 0.00 & -9.7 & SIZE \\
\hline
\end{tabular}

\subsection{Model Estimation via Combined Data}

In order to choose proper method for estimating research model in different periods and times of combined data, Chow test is used. The results of this test are shown in table 2. As it is shown, as we the meaningfulness level is $0.001 \mathrm{so} \mathrm{HO}$ is denied in more than 95\% assurance and panel data method is accepted. Moreover, for panel method test with fixed effects and random impacts Hausman test is used. As meaningfulness level of Hausman test is 0.01 , therefore $\mathrm{HO}$ is denied (random method) and fixed effects method is accepted. 
Table 2. Results of Chow test

\begin{tabular}{|l|c|c|c|c|l|l|}
\hline Test type & Test result & $\boldsymbol{p}$ - $\boldsymbol{v}$ & F statistic & model & Chow test \\
\hline \hline Panel data & H0 is denied & 0.001 & 3.50 & model & Intercept consistency of sections \\
\hline Test result & Test results & p.v & Chi.sq & model & Hausman test \\
\hline Fixed effects & H0 is denied & 0.001 & 21.03 & model & No association between independent variables and regression estimation error \\
\hline \hline
\end{tabular}

\section{Results of Testing Research Hypotheses}

Table 3 shows the results of regression model fitness in combined data level:

Table 3: Results of Testing Research Hypotheses

\begin{tabular}{|c|c|c|c|c|c|}
\hline F-Statistic P.V & p. v & T student & \multicolumn{2}{|c|}{ Coefficient } & Deseription \\
\hline \multirow{4}{*}{} & 0.00 & 6.8 & 112.2 & $\beta_{0}$ & Intercept \\
\cline { 2 - 7 } & 0.00 & -2.99 & -0.70 & $\beta_{1}$ & CRATIO \\
\cline { 2 - 7 } & 0.00 & 3.11 & 0.31 & $\beta_{2}$ & LEVE \\
\cline { 2 - 7 }$(0.00)$ & 0.01 & -2.49 & -0.15 & $\beta_{3}$ & ROA \\
\cline { 2 - 6 } & 0.00 & -3.9 & -0.77 & $\beta_{4}$ & ROE \\
\cline { 2 - 6 } & 0.41 & -0.81 & -1.87 & $\beta_{5}$ & SIZE \\
\cline { 2 - 6 } & 0.00 & -2.64 & -2.47 & $\beta_{5}$ & PROFIT \\
\hline \multicolumn{3}{|c|}{1.867} & & \multicolumn{5}{c|}{ Durbin-Watson stat } \\
\hline \multicolumn{2}{|c|}{0.34} & & \multicolumn{5}{c|}{ Adjusted R-squared } \\
\hline
\end{tabular}

As shown in table $3, \mathrm{~F}$ regression statistic is meaningful in assurance level of $95 \%$. Therefore, research model is meaningful and controller and independent variable can describe dependent variable. Moreover, the adjusted coefficient of determination of test is 0.34 . This shows that almost $0.34 \%$ of dependent variable that is timeliness of annual financial reports of companies result from independent variables in the model and the rest $0.66 \%$ change comes from other factors.

Also considering the amounts of Durbin-Watson stat statistic shows that there is no coefficient between elements of model distribution because they range between 1.5 and 2.5 .

\section{Research Hypotheses Interpretation}

Hypothesis 1: there is a meaningful relationship between current ratio and timely annual financial reports of companies.

The dependent variable in this hypothesis is timeliness of annual financial reports of companies (TIME) and the independent one is current ratio (CRATIO). In fact, this test determines meaningfulness of ratio and the direction of their effects on dependent variables. T student is the related statistic for determining meaningfulness of ratios. The results of testing research model and t statistic of $\mathrm{H} 1$ is shown in table 3 . The results show that $t$ student amount and $\mathrm{p}$-value for $\mathrm{H} 1$, that is current ratio, are -2.99 and 0.00 . According to the fact that the considered error level for this research is 0.05 , CRATIO has meaningful effect on timeliness of financial reports of companies and it is confirmed $95 \%$. The results of this hypothesis is in line with Esmail and Chendler (2005), Wang and Sung (2006), Khodamoradi et al (2013) and is opposite of Mahajan and Chender (2005), Ubert (2010) and Mustafa and Shivat (2013).

Hypothesis 2: there is a meaningful relationship between financial leverage and timely annual financial reports of companies.

The results show that $t$ student and p-value amounts of $\mathrm{H} 2$ are accordingly 3.11 and 0.00 . According to the fact that the considered error level for this research is 0.05 , financial leverage has meaningful effect on timeliness of financial reports of companies and it is confirmed $95 \%$. Ratio of second independent variable is positive. That is, the higher the financial leverage, the later the reports. So the companies will have delay in providing their financial reports and timeliness will reduce.

The results of this hypothesis is in line with Esmail and Chendler (2005), Mustafa and Shivat (2013) and Moradi and Pour Hosseini (1388). It differs from Mahajan and Chender (2005), Ahmad and Abedin (2009) and Asadi et al (2011).

Hypothesis 3 : there is a meaningful relationship between asset return and timely annual financial reports of 
companies.

The results show that $t$ student and $p$-value amounts for $\mathrm{H} 3$ are -2.49 and 0.01 . According to the fact that the considered error level for this research is 0.05 , asset return has meaningful effect on timeliness of financial reports of companies and it is confirmed 95\%. Ratio of third independent variable is negative. That is, the more the asset returns of company, the sooner the reports. So the company will increase providing financial reports this way.

The results of this hypothesis is in line with those of Mustafa and Shivat (2013), Khodadadi and Arabi (2012) and Bani Mahd and Mohseni Sharif. Yet it differs from results of Hav et al (2000).

Hypothesis 4: there is a meaningful relationship between stock holders' salary return and timely annual financial reports of companies.

Results show that $t$ student and $p$-value amounts for $\mathrm{H} 4$ are -3.9 and 0.00 . According to the fact that the considered error level for this research is 0.05 , stock holders' salary return has meaningful effect timeliness of financial reports of companies and it is confirmed $95 \%$. Ratio of forth independent variable is negative. That is, the more the stock holders' salary return, the sooner the reports. So the company will increase providing financial reports this way.

The results of this hypothesis is in line with those of Mustafa and Shivat (2013), Mahdavi and Jamalian Pour (2009). Yet it differs from results of Ahmad and Abedin (2009).

Hypothesis 5: there is a meaningful relationship between company size and timely annual financial reports of companies.

The results show that $t$ student and p-value amounts for $\mathrm{H} 5$ are -0.8 and 0.41 . According to the fact that the considered error level for this research is 0.05 , company size has no meaningful effect on timeliness of financial reports of companies and it is not confirmed $95 \%$.

The results of this hypothesis is in line with Esmail and Chendler (2005), Wang and Sung (2006), Khodadad and Arabi (2012) and is opposite of those of Khodamoradi et al (2013).

Hypothesis 6: there is a meaningful relationship between company profit and timely annual financial reports of companies.

Results show that t student and p-value amounts for $\mathrm{H} 6$ are -2.64 and 0.00 . According to the fact that the considered error level for this research is 0.05 , company profit has meaningful effect on timeliness of financial reports of companies and it is confirmed 95\%. Ratio of sixth independent variable is negative. That is, the more the company profit, the sooner the reports. So the company will increase providing financial reports this way.

The results of this hypothesis is in line with those of Esmail and Chendler (2005), Wang and Sung (2006), Mahajan and Chender (2008) and Khodadai and arabi (2012). Yet it differs from results of Khoda moradi et al (2012) and Mostafa and Shivat (2013).

\section{Discussion and Conclusion}

Deciding about time of providing financial reports is one of the most important subjects which must be considered by managers. From users of financial reports' point of view, timely financial reports are important and useful in accounting because timeliness of information can help users in using better and more useful information. Timeliness is one of the features of information relativity and it means that financial information must be handed to users when they have enough time to make decisions and judgments. Therefore, capital markets consist in publishing information in proper time equally so that the users can have equal access to these information and we can have equal based deals and the information cannot be published as rumors. This research studied the relationships between accounting variables and timeliness of annual financial reports in Tehran's stock exchange. The results showed that current ratio, return of assets, stick holders' salary return and profitability has negative and reverse relationship with timeliness of financial reports and they reduce days of delay in financial reporting and provide timely financial reports. The results also showed that there is a direct positive relationship between financial leverage and financial report timeliness yet there is no meaningful relationship between company size and financial reporting.

\section{Research Suggestions}

1- It is suggested to have more accuracy and control on the companies with less reporting speed.

2- It is suggested that capital market managers provide more strict rules for financial reporting because 107 days of delay is the average financial reporting delay and it can cause a lot of decision making errors for users of these reports.

3- It is suggested to auditory institutions to avoid financial reporting delays according to the results of this 
research and fulfill the risk of untimely reporting.

4- As it is shown in the results, company size has no role in timeliness of reporting, therefore it is suggested that companies use powerful internal and accounting systems in order to increase their reporting's timeliness.

\section{References}

Asadi, Gholam, Baghomian, Rafik and Jutad, Kamrani (2011). Evaluation of the relationship between Company Features and Timeliness of Financial Reporting. Experimental Studies Quarterly, № 33.

Etemadi, Hossein, and Akram Yarmohammadi (2007). Evaluation of Effective Factors on timely Inter-period Reports in Accepted Companies in Tehran Stock Exchange. Accounting Developments Magazine, № 2.

Khodadadi, Vali, Mehdi, Arabi and Fereshteh Taheri Deh Ghotbi (2012). Evaluation of Relationships between Financial Operation of Company and Timing of Financial Reporting. Experimental Studies of Financial Accounting, No 6.

Khoda Moradi, Saeid and Mohammad Javad Sheikh and Mohammad Mehdi Abrishami (2012). Evaluation of Effective Factors on Delay of Intra-period Financial Reporting. Experimental Accounting Researches, No 10.

Soleimani Amiri, Gholam Reza and Atefeh Rahimi Tamrin (1393). Evaluation of Timely Financial Reporting and Functionality of Accepted Companies in Tehran's Stock Exchange. Experimental Accounting Researches, № 11.

Moradi, Mehdi and Mehdi Pour Hosseini (2009). Evaluation of the Relationship between some Financial and non-financial Features and Period of Auditory process. Experimental Accounting Researches, № 1

Mahdavi, Gholam Hossein and Mozafar Jamalian Pour (2009). Evaluation of Effective Factors on Speed of Financial Reporting. Financial Accounting Researches. No 6.

Ahmad, A. , \& Abidin, S. (2009). Audit delay of listed companies: A case of Malaysia. International business research, 1(4), P32 .

Ismail, K. N., \& Chandler, R. (2004). The Timeliness of Quarterly Financial Reports of Companies in Malaysia. Asian Review of Accounting. , 12, 1-18

Mahajan, P., \& Chander, S. (2008). Determinants of Timeliness of Corporate Disclosure of Selected Companies in India. The Icfai University Journal of Accounting Research , 7.

Wang, J., \& Song, L. (2006). Timeliness of Annual Reports of Chinese Listed Companies. Journal of Chinese Economics and Business Studies, 4, 241-257. 